Open Access

\title{
Erratum to: Volume 1, Journal of Chinese Studies
}

Springer Berlin Heidelberg

* Correspondence: editorial@jchinesestudies.com The online version of the original article can be found under doi:10.1186/s40853-016-0002-z. Heidelberger Platz 3, 14197 Berlin, Germany
Due to a technical problem with the set-up of Journal of Chinese Studies in production, the articles [1-4] were published with the incorrect volume and year information in the PDF of the article. In the HTML versions of the articles [1-4], the articles were published with incorrect volume information. The articles [1-4] were published into volume 2 and year 2017; however they should have been published in volume 1 and year 2016.

Each article [1-4] has since been updated with the correct volume and year information and is also listed with the correct information in the references in this erratum.

The publisher takes full responsibility for this error and sincerely apologies for the inconvenience caused.

Received: 7 February 2017 Accepted: 7 February 2017

Published online: 22 March 2017

\section{References}

1. McBride Evil in the philosophy of Karl Marx. Journal of Chinese Studies (2016) 1:1. DOI 10.1186/s40853-016-0003-y

2. Zhengge and Renjun Productivity growth in China's large industrial firms: patterns, causes, and implications. Journal of Chinese Studies (2016) 1:2. DOI 10.1186/s40853-016-0004-x

3. Waxman et al. Development of an observation instrument to measure flourishing learning environments. Journal of Chinese Studies (2016) 1:3. DOI 10.1186/s40853-016-0005-9

4. Han Historical geography and environmental history in China. Journal of Chinese Studies (2016) 1:4. DOI 10.1186/ s40853-016-0002-z 